\title{
THE IMPORTANCE OF ORE RAW MATERIALS BASICITY IN TERMS OF THEIR COMPREHENSIVE QUALITY EVALUATION
}

\author{
Petr BESTA, Leo LUZAR \\ VSB - Technical University of Ostrava, Ostrava, Czech Republic, EU, petr.besta@vsb.cz, \\ leo.luzar@st.vsb.cz
}

https://doi.org/10.37904/metal.2020.3644

\begin{abstract}
Basicity is one of the key chemical criteria in evaluating the properties of ore raw materials. The alkaline character of the blast furnace charge affects the efficiency of the iron production process in the blast furnace. The basicity of the raw ore material also affects the cost of the process, which may require additional basic additives. However, raw ore materials can be evaluated according to a range of criteria, which may be physical, chemical, economic or technological in character. In each category, many other criteria can be identified. Metallurgical companies have long endured problems in selecting suitable raw ore types and other input sources. Complications generally arise because of the wide spectrum of criteria, but also their varying character, which is difficult to uniformly assess. The range of criteria can be evaluated in categorically different units, which is then difficult to compare at an overall level. The significance and influence of basicity in relation to other key criteria in assessing ores was experimentally assessed in this research. The overall quality of the selected ores was also assessed under this task. Ore quality was analysed according to key criteria, which vary in character. Research was conducted at the company TŘINECKÉ ŽELEZÁRNY, a.s. The article discusses the results of research on the significance of basicity in the assessment criteria structure for ores and demonstrates the possibility of assessing ores using mathematical tools.
\end{abstract}

Keywords: Basicity, ore, evaluation, costs, blast furnace, process

\section{INTRODUCTION}

The blast furnace charge consists of fuel, metallic raw materials and slag-forming additives in a mutual ratio that guarantees the result of a certain amount of pig iron with the required chemical properties. The purpose of the fuel is to supply the blast furnace with the required amount of heat and reducing agent, carburize the iron until it is saturated, and create a solid structure in the lower part of the blast furnace to support the flow of gas through the charge at temperatures which soften and gradually melt the ores [1]. The metallic component introduces a sufficient amount of iron in the form of oxides into the blast furnace. The main elements of the metallic component are agglomerate, pellets, or chunks of ore; the ferrous output or residue from steel processes can also be processed. Slag-forming additives are compounds whose purpose is to remove unreduced oxides and sulphur from the blast furnace in the form of slag with certain chemical and physical properties [1]. Limestone or dolomite are frequently used materials.

The greatest portion of the slag-forming additives is added to the agglomeration charge and enters the blast furnace process as agglomerate. A significantly smaller portion of elements that operatively compensate for the alkalinity of the agglomerate and all other raw materials are supplied directly to the blast furnace.

In the Czech Republic, raw ore materials from nearby deposits such as Ukraine or Russia have been used for a long time. Ores from these areas are generally characterized by a higher iron content but also contain a greater amount of impurities which are predominantly acidic in composition. When these ores are processed 
in a blast furnace, a sufficient quantity of alkaline additives is required to balance the overall ratio of acidic and alkaline substances.

The article assesses the significance of basicity in the criteria system which aids us in assessing blast furnace raw materials. The research employed multi-criteria decision-making tools to compare the significance of the assessed criteria. The significance of basicity was also verified in an assessment of overall ore quality. Processed data concerning the quality of raw ore materials were obtained for the research from the company TŘINECKÉ ŽELEZÁRNY, a.s.

\section{PROBLEM FORMULATION}

The blast furnace's input raw materials can be assessed according to a number of criteria. They can be classified according to their similarity into several groups. One possible definition of the categories is as follows [modified 2]:

\section{a) Chemical properties}

The primary content is iron and certain impurities ( $\mathrm{S}, \mathrm{P}, \mathrm{Zn}, \mathrm{Pb}, \mathrm{Zn}, \mathrm{As}, \mathrm{Na}_{2} \mathrm{O}, \mathrm{K}_{2} \mathrm{O}$ ). Other important properties include the degree of iron oxidation and alkalinity. The metal content of the ore from any given site can range between $45-70 \%$ [3]. Highly rated deposits are characterized by an average iron content of $65 \%$ [4].

\section{b) Physical properties}

Physical properties include moisture content, lumpiness, density, porosity and magnetic properties. Physical properties can significantly affect not only the technological aspect of the process but also its final cost, i.e. the cost of the produced iron. In this regard, high moisture, porosity $\left(\mathrm{H}_{2} \mathrm{O}\right.$ content), or inhomogeneity of material lumpiness are factors.

\section{c) Technological properties}

Technological properties significantly affect the effectiveness of the technological process. Strength is the first important property of ore materials. Strength is measured by performing a standardized tumbler test. During rotation, the material is abraded against the bottom of a drum and other parts. The resistance/tumbler index of the ore is then measured according to the proportion of ore grains whose size is greater than $6.3 \mathrm{~mm}$. The abrasion index is also determined according to the percentage of grains smaller than $0.5 \mathrm{~mm}$. After the tumbler test, the material is sorted on certified sieves, and the percentage of materials of these dimensions is determined. The second important technological property is the ore's reducibility. This property determines the rate of conversion of the material's iron ore content into metal by a reducing agent. The key parameter in reducibility is the change in mass of the reduced sample over a defined period as a result of the transition of oxygen from a solid to gaseous state. The third important group is thermoplastic properties. These are the temperatures which begin to soften ore and the temperatures when softening ends. The difference between these temperatures can be called the softening interval. Measurement consists in loading the ore sample while increasing heat. For production in the blast furnace to be technologically effective, it is important that the softening temperature of the ore is kept as high as possible while maintaining a slightly below the temperature when softening ends [2].

From the given list of ore properties, it is evident that only relevant parameters are necessary to consider in an assessment. A significant criterion is basicity, which is key to creating the blast furnace slag. We can measure basicity as the proportion of acidic and alkaline components. In this regard, we can define basicity as either narrow or wide. Narrow basicity is the ratio of the dominant alkaline and acidic components (Equation 1). 


$$
B_{1}=\frac{\mathrm{CaO}}{\mathrm{SiO}_{2}}
$$

Broad basicity includes other compounds, for example $\mathrm{MgO}, \mathrm{Al}_{2} \mathrm{O}_{3}$ (Equation 2).

$$
B_{2}=\frac{\mathrm{CaO}+\mathrm{MgO}}{\mathrm{SiO}_{2}+\mathrm{Al}_{2} \mathrm{O}_{3}}
$$

The target alkaline compounds are therefore $\mathrm{CaO}$ and $\mathrm{MgO}$, and the acidic compounds are $\mathrm{SiO}_{2}$ and $\mathrm{Al}_{2} \mathrm{O}_{3}$. If we convert the alkaline components to one side of the equation in Equations 1 and 2, we obtain the total amount of alkaline ingredients (Equations 3,4).

$\mathrm{CaO}=\mathrm{B}_{1} \cdot \mathrm{SiO}_{2}$

$\mathrm{CaO}+\mathrm{MgO}=\mathrm{B}_{2}\left(\mathrm{SiO}_{2}+\mathrm{Al}_{2} \mathrm{O}_{3}\right)$

If we subtract the alkaline and acidic components (Equations 5, 6), we obtain the total amount of free bases. This can be defined as an excess or deficiency of alkaline components in the feedstock for the blast furnace process.

$\overline{R O}_{m}=C a O_{m}-B_{1} \cdot \mathrm{SiO}_{2, \mathrm{~m}}$

$\overline{R O}_{m}=\mathrm{CaO}_{m}+\mathrm{MgO}-\mathrm{B}_{2}\left(\mathrm{SiO}_{2, m}+\mathrm{Al}_{2} \mathrm{O}_{3, m}\right)$

Alkalinity can then be assessed for any input raw material. It is critical that the overall ratio of alkaline and acidic components is at least equal. In terms of the produced blast furnace slag, alkalinity values fall in the interval 0.8-1.2. The content of alkaline and acidic components themselves, which were given as $\mathrm{CaO}, \mathrm{MgO}$, $\mathrm{SiO}_{2}$, and $\mathrm{Al}_{2} \mathrm{O}_{3}$, constitute the overall slag content 94-96\% [4], [5].

\section{EXPERIMENTAL WORK}

The research conducted at the company TŘINECKÉ ŽELEZÁRNY, a.s., assessed the significance of basicity according to a defined set of criteria. At the same time, the overall quality of three selected ores was evaluated. The raw ore materials originated from the Kursk, Krivoy Rog, and Kovdor deposits. Six key criteria were selected for the assessment:

$\mathrm{K} 1-\mathrm{Fe}$ content $(\%)$

K2 - Basicity (-)

K3 - Homogeneity of lumpiness (\%)

K4 - Moisture content (\%)

K5 - Reducibility (\%)

K6 - Strength (\%) 
The above-mentioned ore's overall quality was determined from the criteria values. The criteria were selected with regard to other possible operational uses in assessing supplied ores. The first step in assessment was establishing the weight of the individual criteria. This step also identified the position of basicity in the defined set of criteria. Saaty's principle, based on criteria pair comparison, was applied in the assessment.

This was done using a scale of absolute values (Table 1) and allows simple processing of measurable and non-measurable quantities with the aid of expert opinion. An expert's assessment can often provide a more precise interpretation if the numbers are precisely defined [6].

Table 1 Numerical expression of the significance of preferences [7]

\begin{tabular}{|c|c|}
\hline \multicolumn{2}{|c|}{ Expression of preferences } \\
\hline Numeric & Verbal \\
\hline 1 & The criteria are equally significant \\
\hline 3 & The first criterion is slightly more significant than the second \\
\hline 5 & The first criterion is strongly more significant than the second \\
\hline 9 & The first criterion is very strongly more significant than the second \\
\hline
\end{tabular}

The sizes of the preferences of the $i$-th criterion against the $j$-th criterion can be entered in Saaty's matrix, whose elements $s_{i j}$ represent the estimates of the proportion of criteria weights (how many times a criterion is more significant than the other) [8], according to Equation (7).

$s_{j i}=\frac{v_{i}}{v_{j}}$

where:

$v_{i, j}$ - weights of the selected criteria

The matrix is reciprocal, and the value on its diagonal are all one. This is because each criterion is equivalent in itself [8]. The weights of the criteria can be determined by calculating the standardized geometric diameter, according to Equation (8).

$w_{i}=\frac{\left[\prod_{j=1}^{n} s_{i j}\right]^{1 / n}}{\sum_{k=1}^{n}\left[\prod_{j=1}^{n} s_{k j}\right]^{1 / n}}$

The assessed criteria were compared in pairs according to the scale given in Table 1. Saaty's matrix was then completed according to the pair comparison. As an example, the comparison of $\mathrm{K} 1$ (Fe content) and criterion K2 (Basicity) can be highlighted. Criterion K1 obtained a slightly more significant than value 3 . Therefore, the value 3 was placed in position a12 in the matrix, and under the main diagonal of the matrix, the value $1 / 3$ was placed in position a21. Saaty's matrix (9) was then completed for all pair decisions. The consistency of the matrix was then measured. This corresponds to the value of the given size of the matrix. 


$$
s=\left(\begin{array}{cccccc}
1 & 3 & 5 & 5 & 7 & 9 \\
1 / 3 & 1 & 3 & 3 & 5 & 7 \\
1 / 5 & 1 / 3 & 1 & 1 & 3 & 5 \\
1 / 5 & 1 / 3 & 1 & 1 & 3 & 5 \\
1 / 7 & 1 / 5 & 1 / 3 & 1 / 3 & 1 & 3 \\
1 / 9 & 1 / 7 & 1 / 5 & 1 / 5 & 1 / 3 & 1
\end{array}\right)
$$

A standardized geometric average of rows was used to evaluate the matrix and set the weights (Equation 8).

Table 2 shows the individual steps of the calculation and the final weights of the criteria.

Table 2 List of criteria weights

\begin{tabular}{|l|c|c|c|c|c|c|}
\hline Criterion & K1 & K2 & K3 & K4 & K5 & K6 \\
\hline Geometric average & 4.0963 & 2.1716 & 0.9998 & 0.9998 & 0.4603 & 0.2440 \\
\hline$\sum$ & \multicolumn{7}{|c|}{8.9721} \\
\hline Weight (-) & 0.4565 & 0.2420 & 0.1114 & 0.1114 & 0.0515 & 0.0272 \\
\hline Weight (\%) & 45.65 & 24.20 & 11.14 & 11.14 & 5.15 & 2.72 \\
\hline
\end{tabular}

Based on quantified pairwise comparisons, the iron content (K1 - 0.4565) has the greatest significance. The second most significant is basicity (K2 - 0.2420). These two criteria can be considered essential, as their overall significance is $69.85 \%$. According to Pareto's rule, these are therefore considered key criteria. The significance of basicity itself in a set of defined criteria may also be assessed as significant. The value of the weight of basicity is many times higher than the other criteria. These criteria weights were applied in determining the overall quality of the three ores. Table 3 shows the specific values for the defined criteria.

Table 3 Criteria values for selected ores

\begin{tabular}{|c|c|c|c|c|}
\hline \multirow{2}{*}{ No. } & Criteria & \multicolumn{3}{|c|}{ Ore deposits } \\
\cline { 2 - 5 } & Ke content (\%) & Kursk & Krivoy Rog & Kovdor \\
\hline K1 & Basicity (-) & 65 & 61 & 40 \\
\hline K2 & Homogeneity of lumpiness (\%) & 0.7 & 1.3 & 55 \\
\hline K3 & Moisture content (\%) & 51 & 53 & 8.1 \\
\hline K4 & Reducibility (\%) & 5.7 & 67 & 64 \\
\hline K5 & Strength (\%) & 65 & 74 & 71 \\
\hline K6 & & 75 & & 5.5 \\
\hline
\end{tabular}

A multicriteria decision-making method was used to determine the overall quality of the raw ore material. The method is based on measuring Euclidean distance and is also referred to as the distance from the ideal variant. The principle of the method lies in quantifying the partial deviations of each criterion from the best value. Each difference is simultaneously normalized by the corresponding criterion weight. We can determine the distance from the ideal variant using Equation 10.

$D=\sum_{i=1}^{n} v_{i}\left(\frac{x_{i}^{*}-x_{i j}}{x_{i}^{*}-x_{i}^{0}}\right)^{2}$ 
where:
$D$ - the distance from the ideal variant
$v_{i}$ - the weight of the criteria
$x_{i}^{*}$ - the length of action
$x_{i j}$ - the mean width of the elongated bar
$x_{i}^{0}$ - the mean width of the elongated bar

Equation 10 is a modification of a commonly used relationship to determine the distance from the ideal variant. The relationship which subsequently squares the final sum of partial deviations is standardly used. However, this operation may reduce the detected differences in the identified distance. A simplified form of the relationship was therefore applied.

Table 4 Principle of calculating the distance from the ideal variant

\begin{tabular}{|c|c|c|c|c|c|c|c|}
\hline No. & Criteria & $v_{i}$ & $\boldsymbol{x}_{i}^{*}$ & $x_{i}^{0}$ & Kursk & Krivoy Rog & Kovdor \\
\hline K1 & Fe Content (\%) & 0.4565 & 65 & 40 & 0 & 0.0116 & 0.4565 \\
\hline $\mathrm{K} 2$ & Basicity (-) & 0.2420 & 1.3 & 0.7 & 0.2420 & 0 & 0.0268 \\
\hline K3 & Homogeneity of lumpiness (\%) & 0.1114 & 55 & 51 & 0.1114 & 0.0278 & 0 \\
\hline K4 & Moisture content (\%) & 0.1114 & 5.5 & 8.7 & 0.0004 & 0 & 0.1114 \\
\hline K5 & Reducibility (\%) & 0.0515 & 67 & 64 & 0.0228 & 0 & 0.0515 \\
\hline K6 & Strength (\%) & 0.0272 & 75 & 71 & 0 & 0.0017 & 0.0272 \\
\hline & & \multicolumn{3}{|c|}{ D (-) } & 0.3766 & 0.0411 & 0.6734 \\
\hline & & \multicolumn{3}{|c|}{ D (\%) } & 34.52 & 3.77 & 61.71 \\
\hline & & \multicolumn{3}{|c|}{ Rank } & 2. & 1. & 3. \\
\hline
\end{tabular}

Table 4 demonstrates the entire principle of the calculation. For each criterion, a weight, the best and worst values, and the partial distance from the ideal variant for each ore are given. The sum of the partial deviations represents the final distance according to the results of calculation using Equation 10. Following the principle of the method, the best ore variant will be the least distant from the ideal variant. The final ores ratings were determined according to this principle. The percentage value of distance for each ore was also determined from the sum of all distances (Table 4).

\section{RESULTS AND DISCUSSION}

The defined criteria were compared using Saaty's method. On the basis of pair decisions, two key criteria were identified (iron content, basicity). The significance of basicity as the second most important of criterion is clear. The value of the weight of basicity was comparable to the sum of the weights of the other three criteria. The ore injected into the blast furnace charge may be rather acidic, especially its metallic components, and therefore it is critical to examine the ratio of acidic and alkaline constituents. Basicity is a key characteristic in forming slag in the blast furnace. Slag must possess a chemical composition which desulfurizes the iron and ensures the complete reduction of iron and other elements, and also be sufficiently fluid to flow easily out of the blast furnace. Fluidity is also related to chemical composition and the content of some compounds (FeO, $\mathrm{MnO}$ ). Besides criteria weights, the overall quality of three ores were determined. The properties were compared by applying a modified distance method from the ideal variant. The Krivoy Rog deposit (distance from the ideal variant $0.0411,3.77 \%)$ supplied the best rated ore. Ore from the Kursk deposit $(0.3766,34.52 \%)$ was rated second. At this point, it can be mentioned that this ore had the highest iron content, despite not 
being rated the best in overall quality in the final assessment. Ore from the Kovdor deposit $(0.6734,61.71 \%)$ was rated last. The values indicate a large difference in quality between the ores. In the best rated ore, the final value was significantly affected by basicity, which was the highest of the three ores (1.3). The results from a defined set of criteria show that this method of assessment may be used as a basis for managerial decisions in selecting ores.

\section{CONCLUSIONS}

Input raw materials can be assessed according to a wide range of criteria. These criteria may be chemical, physical or technological in character. The research verified the high significance of basicity as one of the most important chemical criteria. The weights of the criteria were determined from pair comparisons. The applied method's advantage is easy substitution of the number of criteria and its algorithmic simplicity. The overall quality of the ores was determined using the identified weight criteria. The method allows categorially different criteria to be quantified and evaluations to be transformed into a single indicator. The significance of basicity in the structure of the assessment of ores was also confirmed. The demonstrated method permits easy use in practice to compare multiple ore types and may be applied in the purchasing departments of metallurgical companies to assess the range of input raw materials available. Precisely quantifying the proportion of acidic and alkaline elements in the input raw materials is essential. Any deviations must be regulated during the blast furnace process. Overall, basicity is a key factor of the overall quality of the ore charge. Apart from technological conditions, basicity also affects the cost of pig iron production. Strongly acidic ore raw materials require a greater quantity of alkaline additives, which are supplied primarily during the agglomeration process. The importance of basicity can therefore be seen at several levels. In a very similar manner, the effect of a number of other criteria during the blast furnace process can be evaluated. Most decisions in this area are therefore multi-criteria decisions. In the current highly competitive environment, it is crucially important for metallurgical companies to use tools that will enable them to manage and evaluate these multifaceted problems.

\section{ACKNOWLEDGEMENTS}

The work was supported by the specific university research of the Ministry of Education, Youth and Sports of the Czech Republic No. SP2020/61.

The article was created thanks to the project No. CZ.02.1.01/0.0/0.0/17_049/0008399 from the EU and $C R$ financial funds provided by the Operational Programme Research, Development and Education, Call 02_17_049 Long-Term Intersectoral Cooperation for ITI, Managing Authority: Czech Republic Ministry of Education, Youth and Sports.

\section{REFERENCES}

[1] BROŽ, L. Hutnictví železa. Praha: SNTL - Nakladatelství technické literatury, 1998.

[2] KRET, J. Teorie procesů při výrobě železa. Ostrava: VŠB- TUO, 2013.

[3] SMALLMAN, R. E. Modern Physical Metallurgy. Tokyo: Butterworth-Heinemann, 2013.

[4] GEERDES, M., TOXOPEUS, H., COR, V. Modern Blast Furnace Ironmaking. Amsterdam: IOS Press, 2010.

[5] VIGNES, A. Extractive Metallurgy 1: Basic Thermodynamics and Kinetics. New York: John Wiley \& Sohn, 2013.

[6] FIALA, P. Modely a metody rozhodováni. Praha: Oeconomica, 2012.

[7] FOTR, J., ŠVECOVÁ, L. Manažerské rozhodování. Praha: Ekopress, 2016.

[8] RAMíK, J. Vícekriteriální rozhodování - analytický hierarchický proces (AHP). Karviná: Slezská univerzita v Opavě, 1999. 